\title{
Important Description of a Minimally Invasive Procedure for Axillary Osmidrosis
}

Borut I. E. Jemec ${ }^{1}$

Received: 24 May 2015/Accepted: 12 August 2015/Published online: 16 September 2015

(C) Springer Science+Business Media New York and International Society of Aesthetic Plastic Surgery 2015

Level of Evidence $V$ This journal requires that authors assign a level of evidence to each article. For a full description of these Evidence-Based Medicine ratings, please refer to the Table of Contents or the online Instructions to Authors www.springer.com/00266.

To the Editor,

I agree with Dr Wiwanitkit that reviewing the literature carefully before publishing a new method is a hall-mark of good research [1]. The description of the minimally invasive technique for treating axillary osmidrosis or hyperhidrosis surgically by "subcutaneous curettage combined with trimming through a small incision" is, however, somewhat older than suggested, dating from 1975 and not $2014[2,3]$.

While one may find consolation in the fact that imitation is the sincerest of flattery, one may also worry about the quality of the research. Our speciality has the potential to gain significant professional recognition from more stringent research. Research is valuable and significant even if one does not invent the method studied.

\section{Compliance with Ethical Standards}

Conflict of interest The author declares that he has no conflicts of interest to disclose.

\section{References}

1. Wiwanitkit V (2015) Minimally invasive procedure for axillary osmidrosis. Aesthet Plast Surg 39(3):454

2. Jemec B (1975) Abrasio axillae in hyperhidrosis. Scand J Plast Reconstr Surg 9(1):44-46

3. Jemec B, Holm Hansen B (1978) Follow-up of patients operated on for axillary hyperhidrosis by subcutaneous curettage. Scand $\mathbf{J}$ Plast Reconstr Surg 12(1):65-67
Borut I. E. Jemec

borutjemec@yahoo.de

Vilvordehoej 8, 2920 Charlottenlund, Denmark 